\title{
Improving understanding of service user involvement and identity: Disabled people bringing ourselves out of the half-shadows
}

\author{
Colin Cameron ${ }^{1}$, Michele Moore ${ }^{2}$ and Ann $\mathrm{Nutt}^{3}$
}

\begin{abstract}
We are a group of disabled service users 'whose experiences are semi-visible or semi-acknowledged within normative discourses'. We have conducted research with other disabled service users to circumvent challenges of research co-production and facilitate inclusion in research of ourselves and our disabled peers who are frequently described as 'hard to reach'. We carried out this research in order to enhance our own visibility as researchers and bring our experience as disabled service-user representatives out of the 'half shadows'. In doing this we hoped to expand awareness of the dynamics at play in service user-representation. This research arose directly out of the concerns of the late Patricia Chambers, a disabled woman who expressed deep concern about how her experience as a service user -representative was routinely rendered semi-visible or semi-acknowledged within normative discourses. It begins to explore the extent of our rendition to the halfshadows and to work out strategies for bringing our experience in to the light.
\end{abstract}

Keywords: research access; visibility; service users; user-led research; experience

1. Department of Social Work, Education and Community Well Being, Faculty of Health and Life Sciences, Northumbria University

2. Patient Safety Academy / QRSTU, Nuffield Department of Surgical Services, John Radcliffe Hospital, University of Oxford

3. Chair, Patient Panel, The Princess Alexandra Hospital NHS Trust, Harlow, UK

Address for correspondence: colin.cameron@northumbria.ac.uk

Date of first (online) publication: 21st March 2020

Acknowledgements: Patricia, Chambers, a prominent member of the black and minority ethnic mental health user/survivor movement and a dear friend and colleague, passed away in May 2016. For over 25 years, Patricia worked tirelessly to address issues at the intersections of race/culture and madness, within services, within the wider user/survivor movement and within research and policy.

In 2009 Patricia took over as the Network Manager of Catch-a-Fiya, the only (and now defunct) national network for people from Black communities. It is impossible to list all the places and platforms she contributed to/through: BUGS, the Afiya Trust, Shaping Our 
Lives, Black Women's Mental Health Project, The Forward Project, the DRE Ambassadors programme, NIMHE's Making a Real Difference programme, the Count Me In census, Dancing to Our Own Tunes.... and the many local/informal user groups where she acted as an advocate and friend to people who needed that.

We developed this project from an interest Patricia had in the conflicts for people who use services and who also work to improve them.

We thank the National Lottery through the Big Lottery Fund for providing funding for this project, the twenty-two people who took part in the research and the four disabled researchers who collected the evidence 


\section{Introduction}

In this paper for the journal's special edition 'In the half shadows' we discuss our research with 'hard to reach populations' when the so-called 'hard to reach population' is ourselves, carrying out research about our own experience. We are a group of disabled service users 'whose experiences are semi-visible or semiacknowledged within normative discourses'. We who have conducted research with other disabled service users positioned likewise, in order to circumvent challenges of research co-production and facilitate inclusion in research of ourselves and our disabled peers who are frequently described as 'hard to reach'. We carried out this research in order to enhance our own visibility as researchers and bring our experience as disabled service-user representatives out of the 'half shadows'. A number of researchers have published on the power dynamics of service user participation including Brosnan (2012) and the voices of different groups of service users commenting from a range of international contexts are beginning to cohere (Beresford and Carr, 2018). Through our research we hoped to expand awareness of the dynamics at play in service user-representation.

The research at the centre of this paper is wholly user-led research designed, carried out, analysed, written up and disseminated by disabled service users. It arose directly out of the concerns of the late Patricia Chambers, a disabled woman who expressed deep concern about how her experience as a service user -representative was routinely rendered semi-visible or semi-acknowledged within normative discourses. Patricia pointed out that many disabled people have regular experience of being asked as 'service user experts' for our views. Within these consultations, what we have to say is often valued and taken seriously. But back in the context of day-to-day experience, a service user's status or identity as 'expert' is forgotten and less respectful power relations resume. Role conflict and role ambiguity is experienced which can leave service users confused over status and concerned about having been used or exploited. This issue was discussed more broadly by members of the leading UK Think Tank Shaping Our Lives, a Disabled People's Organisation run by, and for, disabled people (www.shapingourlives.org. uk). It emerged that in our various roles as service user representatives many of us experience being un-acknowledged and marginalised; our participation is routinely assigned to the 'half-shadows'. Subsequently we as people, although ostensibly being included as service user representatives, remain in the 'half shadows' - being known to exist, asked to inform service planning and delivery, but not being acknowledged or included as equals either within, or outside of, this role. We decided, as a group of disabled service users with shared experience of being insufficiently acknowledged and marginalised, to set up research to explore the extent of our rendition to the half-shadows and to work out strategies for bringing our experience in to the light. This paper reports on that project.

Our work responds to our individual and collective experience of being involved 
as service user representatives in forums where social workers and other service providers acknowledge the importance of bringing our experience out of the 'halflight', yet little attention is paid to the impact of this involvement on the service users who give our time and energy to the role. For some of us it transpires, while inclusion as service user representatives is intended as a strategy to raise our seldom heard voices and involve us in planning and evolving services using our experiential knowledge in its construction, the experience can reinforce feelings of exclusion, diminishment and inequality. We wanted our research to explore ways in which disabled service user representatives feel our inclusion can be improved so that our input to service development, policy and practice is not marginalised or under-utilised but fully acknowledged, productive and personally rewarding. And so, through our research, we aim to bring ourselves out of the shadows and in to the light.

Our paper will describe our project entitled 'Improving Understanding of Service User Involvement and Identity' (Meakin et al, 2017) and report our research findings with the aim of improving understanding of good, and conversely unsatisfactory, experiences of service user involvement in the commissioning, design, delivery and evaluation of public sector services. We consider the challenges faced by service users in negotiating our dual role of being both a service user representative and recipients of services from our own point of view.

Following the research we are able to offer clear practice pointers on how to facilitate the process of service user representation so that it is a positive experience with valuable outcomes for all. We have found that when service user involvement is respectful and inclusive this has a positive and mutually beneficial impact for professionals and service users alike. When arrangements for user involvement do not pay sufficient attention to dismantling barriers to participation, service user representatives experience organisational exclusion; we feel our contribution is not adequately respected and the experience of being involved as service user representatives recycles oppression.

\section{Context}

Shaping Our Lives is a national organisation and network of user-led groups, service users and disabled people established in 1994. We are committed to inclusive involvement and specialise in research and the practice of involving diverse communities in policy, planning and delivery of services. We have worked with health trusts, local authorities, in social work education, and with a broad spectrum of human service providers. Our inclusive approach means that irrespective of people's impairments - whether these are physical, sensory, emotional or cognitive - everyone has an equal say within our work. Through our network of more than 
430 user-led organisations, Shaping Our Lives aims to improve the quality of care and support services people receive by:

- Enabling the inclusive involvement of service users and carers in policy, planning and service delivery nationally and locally so better outcomes are achieved for service users and carers.

- Educating through user-led research and service user perspectives on the cycle of services from planning to evaluation.

- Training professionals to be service user focused and to work inclusively with a diverse range of people and their carers.

- Giving a shared voice to user-controlled organisations and the people who take part in them.

- Enabling groups to link to other user-controlled groups by providing an equal and accessible network.

As a user-led organisation of disabled people, Shaping Our Lives values are underpinned by the social model of disability (Oliver, 1990). This involves making a distinction between impairment and disability: we recognise impairment as a limiting embodied condition or characteristic, and disability as the outcome of an unequal social relationship for people with impairments. Using this definition, disablement can be understood as an experience imposed on top of our impairments by the way we are unnecessarily isolated and excluded from full participation in society' (UPIAS, 1976). Rather than viewing disability as a 'problem' to do with the bodies of individuals, we view disability as a matter of how society responds to, or has failed to respond to, the needs of people with impairments (Cameron, 2014a). We see ourselves not as 'people with disabilities' but as people with impairments who are disabled by society to the extent that society imposes physical, social and cultural barriers as we try to negotiate everyday life (Clark, 2014). These barriers can range from inaccessible buildings and public environments to unwelcoming or complacent attitudes. Working with, and through the social model of disability, has important implications for our work because it enables us to locate the need for change within institutional practices and behaviours which are inherently, if unintentionally, disabling. This theoretical approach informs all of our work and is foundational to our campaign to bring ourselves out of the half-light.

It is important to make the distinction between a social model approach and an individual model approach to understanding disability, because it is the latter which has traditionally shaped the way that services for disabled people have been organised and delivered. McKnight (2005) explained how the traditional relationship between professionals and service users has established the message that disabled people are 'the problem', that service providers have 'the answer', that disabled people cannot come up with 'the answers' to our own concerns and also that the resolution of our problems does not lie in the political, social and economic environment. Within Shaping Our Lives we refute all of these traditional 
assumptions which deficit the role disabled people can play in determining our experience of services.

Despite considerable progress made in recent years in terms of service userinvolvement, attention to 'joint planning', 'co-production' and other strategies intended to be inclusive and empowering of disabled people, at Shaping Our Lives we are still exercised by how long it takes for tangible change to the traditional relationship between service providers and service users described above to occur (Beresford, 2016; Beresford and Carr, 2018). In our discussions it emerged that we commonly identify much tokenism, condescension, and a feeling that organisations only consult with us as service users because they are obliged by good practice guidance rather than because they are committed to doing things differently. We identified a clear need to find out more about the experience of service users as service user representatives.

The social model thinking which runs through everything we do at Shaping Our Lives also determines the emancipatory principles which underlie our approach to research. Our research is always constructed using the social model of disability as the framework for our research production; we only do research where it will be of some practical benefit to the self-empowerment of disabled people and/or the removal of disabling barriers and we take ownership of research ourselves in order to ensure full accountability to disabled people and their organisations (for further discussion of the origins and significance of these principles see Priestley, 1997 as discussed in Cameron, 2014b, p.35). These principles guided the formulation of the research project we decided to carry out building on the concerns of Patricia Chambers.

A prominent member of the black and minority ethnic mental health user/ survivor movement in London, Patricia talked at a Board Meeting in 2015 about a sense of role conflict she felt in being treated on the one hand with respect - as an 'expert by experience' - when involved as a service user representative who had a potential contribution perceived as of value to service provider organisations wishing to engage her - and, on the other hand, outside those situations being relegated to 'just a service user' even by the same professionals who extracted expertise from her service user representation. Patricia observed a contradiction in the treatment she received from service providers with whom she had contact depending on whether she was 'in' or 'out' of the service user representation context; in and out of the halflight determined by whether she was being seen as a service user or a service user representative when, of course, she wished to be treated with equal respect and attributed the same value for being the same person that she was irrespective of the role or moment she was in. When she was involved as a service user representative Patricia observed a respectful formal acknowledgement by service providers of the need to listen to her perspective as key to the successful evaluation and development of services. Yet outside of the situations in which she was seen as a 'service user 
representative' she noticed the relationship between herself and those providers to whose consultations she had just contributed reverted to one characterised by inequality: 'In the meetings they say 'hello Patricia, how are you? But when they next see me on a corridor they act like they don't know me'. As Patricia described these tensions it emerged that her concerns were shared by many members of Shaping Our Lives. Patricia's reflections formed the kernel of our successful bid for research funding to the National Lottery Awards For All programme to find out more about the impact of service user representation on service users and to evolve ideas about how our involvement as service user representatives can be enhanced.

\section{Methods and participant profiles}

We set up a qualitative user-led project to find out:

- How does being a service user representative impact on service users?

- Are there conflicts between our experiences in everyday life and our experiences as service user representatives?

- What do disabled people feel could be done to minimise any conflicts?

Research participants were recruited through Shaping Our Lives network communications to over 470 user-led organisations across the UK, predominately in England. The recruitment materials asked for participants with more than one experience of being a service user representative and/or experience over a number of years.

Twenty-two disabled people agreed to be interviewed for the study. Everyone interviewed had at least two examples of past representation roles and the majority were still actively involved as service user representatives. Approximately a quarter of the respondents had had five or more roles and the same proportion had had ten or more roles. One person listed over twenty different boards and service user advisory roles they contributed to. The types of representation participants had experience of ranged from Partnership Boards in local authorities, Patient Participant Groups in primary and secondary health care, roles in education and voluntary sector structures, advocacy and carer representative positions. There was also mention of local government structures such as Healthwatch, Clinical Commissioning Groups and transport advisory committees. Half of the people taking part also mentioned a role they had with a local charity or user-group for disabled people. In line with Shaping Our Lives policy on participation each interviewee was offered an involvement payment and all associated travel and support costs were met. 


\section{Profiles of participants}

Of the twenty-two participants, twelve were women, nine were men and one person identified as non-binary. The age ranges varied with two participants being under 40 years old and two over 70 years old; the remaining participants were equally split between 41 and 55 years old, and 56 and 70 years old. There were no disabled people under 25 years old in the study. We made strenuous efforts to engage representatives of a hospital based youth service user group. The young people approached were, however, busy with exam commitments and could not fit in an interview. It is also the case that people who take part in representation activities tend to be people who have had many years of using services as an adult. Those who took part had a broad range of impairments and health conditions. There were four people with varying degrees of sight loss including one person describing themselves as 'totally blind' and one deaf person. Among the other participants the following were used to describe our range of impairments and health conditions: acquired brain injury, cognitive impairment, learning difficulties, mental ill-health, non-epileptic seizures, Multiple Sclerosis, Cerebral Palsy, spinal injury, mobility impairment and two people who identified as wheelchair users and having poor mobility. One of the research participants was also a carer of four disabled children.

The data therefore introduces the voices of different groups of service users, starting from our personal experience of service user representation.

\section{Findings}

In relation to how being a service user representative impacts on service users themselves, participants gave many different responses about how involvement and representation activities had made us feel including, most importantly, that being a service user representative can make us feel better about ourselves as service users. Positive responses suggest that being able to help improve policies and services for other service users was satisfying and rewarding including:

- Felt good to be listened to and make a difference

- Felt good to represent people who cannot represent themselves

- I could provide information to improve policies

- Gave me a purpose to help people and not just disabled people

- I felt empowered to talk about issues that affect people like me

- If it is with someone committed (to involving service users) it feels quite good

- An experience 'I valued at the time' (but after it felt tokenistic as it was not acted on). 
However, there were more negative than positive responses concerning the experience of service user involvement. These comments can be viewed in categories of: process, that is the organisation and execution of the involvement activity; or personal difficulties experienced by service users working as representatives.

The poor experiences grouped as 'process' problems suggest a number of issues. Firstly, service user representation activities have no meaningful outcome if the process is inaccessible, inflexible, too long and/or tokenistic. Involvement is particularly unsatisfactory if the voices of the service user representatives are not being listened to or heard. Process issues, of course, relate to power imbalances between the professionals organising the activities and the service users taking part and were described as follows:

- $\quad$ Frustrating as it takes so long to make a difference

- Annoying as it became clear that it was a tick box exercise

- Difficult as there was a set pathway and you had to understand this to make a difference

- I felt patronised as they were not listening to what I had to say

- If it is someone not committed it is depressing, frustrating and head-bangingly annoying

- Pointless as they have their regular service users who get listened to more than others

- Service user input is always at the end of the agenda and the professionals start excusing themselves.

It cannot be overlooked that there are also 'personal' conflicts and difficulties in taking part as a representative for service users and our findings suggest this may be because of the stress it puts on mental health; the general pressures of living with an impairment or health condition; the extensive knowledge needed to take part in some representation activities; sharing lived experiences with other people and sharing experiences with professionals responsible for the care of the representative. However, people who had had good experiences of being involved as service-user representatives had been able to overcome or manage these personal conflicts through supportive and inclusive processes: 'quite complex really, it was difficult but rewarding at the same time' .

'Personal' barriers to service user involvement mentioned include:

- Feeling apprehensive at speaking about an impairment or health condition I may know nothing about

- Difficult if a professional last saw you when you were receiving treatment

- It can be difficult to listen to other people's experiences

- Difficult as people do not give me time to speak (person with a speech impairment)

- Drawing on personal experiences can be distressing and exhausting. 
Respondents also talked about a sense of responsibility and skills needed to speak on behalf of a wide range of service users if this was part of the requirement. One person reflected that it was easy to be a passive recipient of a consultation, but to speak and effect change on behalf of others required you to advocate, critically assess the impact of changes, make clear references in presenting an objection and to be able to think on your feet. Another person talked about needing to grow into a role, listen to what other people had to say and not back people into a corner as this would make discussions difficult.

When asked about how being a service user representative had been a good experience, many benefits of social connection were described:

- Good to be part of a team

- Involvement gave me a sense of purpose

- A feeling of being wanted and needed

- I felt that my knowledge and experience was valuable

- I was motivated and excited when the contribution I made was acknowledged

- Good when it made a difference, there can be a feeling of being stronger through effecting social change.

A number of essential ingredients for a good experience of being a service user representative were identified:

- Equality

- Mutual respect

- Ownership

- Structure

- Commitment

- Feedback

- Personal development

Opportunity for personal development through service user involvement was described in many different ways including participation in training, acquiring new skills, gaining knowledge, opportunity for paid or voluntary work, increased confidence, opportunity to network/make new friends, increased self-worth and finding out about services and organisations in the area. Several people pointed to the importance of opportunities for personal development for a positive experience, for example:

I think the best one for me used to be the Partnership Board because they had a mentoring system and I was getting some training that helped me be a representative. 
Where service providers do not adequately address both personal and practical issues of inclusive involvement, the process of inclusive communications and attitudes is likely to be less enabling for service user representatives. One person said they would have welcomed the opportunity to sit down and talk about what the 'professionals' were trying to achieve, how they were planning to do it and what would be involved before agreeing to become a representative. This would help reduce or even eliminate practical process issues such as finding oneself not being sufficiently supported with access arrangements. We heard many reports of service users being ready to join meetings only to find practicalities such as travel arrangements and parking had not been arranged.

Results further indicate that communication issues are not consistently addressed with due regard to sustain inclusive involvement. Respondents describe a range of procedural shortcomings to do with communication:

- Not being listened to

- Not being given equal power and respect

- Feeling inadequate because information at the heart of discussion items is not equally shared between staff/professionals and those disabled people participating as service user representatives

- Professionals not acting on service user suggestions or giving feedback

- An agenda had been set before the meeting so there is no opportunity to influence the process - a clear indication that service user involvement is not genuinely collaborative

- Service user agenda items are put at the end of the agenda and not discussed because of time constraints (meetings not chaired appropriately

Participants reported feeling intimidated on occasions when we observe our commitment to encouraging a social model perspective gets shifted back to a medical model approach which implies individual parameters to issues, automatically diminishing our contribution and recycling negative solutions to disabled people's issues. Several service user representatives described exposure to negative rhetoric about disabled people in meetings they attended and directly felt the impact of austerity policies diminishing their involvement due to financial pressures on services.

The problems described above, particularly of not being listened to, lead to service users feeling that our knowledge is not valued as explained below:

It is diminishing to realise how service providers see service users. It is frustrating in the meetings to sense how little credence most of them actually give to service user viewpoints. If our view chimes with theirs they are positive and pleased with how things are going; if the service user perspective challenges their views then they tend to offer platitudes and try to swiftly move the discussion on. 
One service user representative described their participation as a 'waste of my time as they were not listening'. Another participant stated that 'the worst' was when the professionals hosting the involvement activity did not value their experience. Another referred to the way health professionals talked about service users as if they were not actually in the meeting and it is common to hear of an assumption that service users will not understand the complexities of the decisions being made in professional meetings. Interestingly, many respondents felt we learned a lot about how to assist our own advocacy from observing the way service providers talk about service users in meetings we are asked to attend.

We set ourselves the question of why, if we are not fully respected as service user experts, this might be so? Our findings suggest there needs to be a cultural change to practice on the ground and not just in policy aspirations, in a way that gives people choice and control over our lives, particularly in the health sector as the following comments encapsulate:

Many professionals mean well but can be tokenistic and patronising, especially in the health sector. It is a huge mind set for health to realise that disabled people want choice and control over their own lives although many disabled people who have not had the same experience as those who get involved in service-user representation simply accept this kind of treatment.

In the worst reports people felt that professionals were not listening to their views or dismissing them altogether:

They are working against me, not with me. They are making decisions on what they think is best for me but not really listening to me.

We are frustrated to have to point out that of course being a service user and a service user representative, and a professional in one's own right are not mutually exclusive. For all respondents our identity as a service user seems to dominate our encounters with professionals - even in the user representative experience of being deemed expert by experience.

Most people thought they were treated differently if a professional was unaware of their service user role, and similarly, treated only as an expert in their own conditions if they were known to be a service user representative, suggesting an a priori assumption of low expertise. The experience of receiving services was reported as a 'top-down' experience, whereas people described their service user representation roles as a more equal relationship where we can challenge decisions and negotiate outcomes. This is attributed to the power imbalance being greater when we are receiving services. For some respondents, the chance to disrupt the usual service user-service provider power imbalance was part of our motivation for taking on and sticking with the representation role. 
The following example illustrates why this might be so:

For example, I went to the customer service area, just as a service user, just for me, and the receptionist was very abrupt.. I just sat there in the waiting room feeling overwhelmed. When I was being a rep I would go straight to the desk and be welcomed.

For others, the power imbalance between themselves and service providers proves intractable:

In some services, regardless of whether I am a service user or a rep, I have been disregarded, patronised and infantilised. It hasn't made any difference if I am rep or not.

Someone else described how difficult it was when they had been working sideby-side with professionals as a representative and then suffered a relapse. They felt there needed to be more thought about the relationships that develop through being a representative and how these are managed if you become unwell:

The hardest part was when I had a relapse everyone had seen me being well, speaking confidently and it is all the harder to fall when you are back at their door, needing their help.

Other comments acknowledged that relationships between service providers and service users 'work both ways' and some professionals feel their own capacity to interact limited or un-nerving, particularly if we have complex needs and are at the same time able to knowledgeably represent ourselves and others.

Our results suggest a tension around the position of service user representatives in the eyes of service providers because as service users we seek their views as providers but as a user representative, professionals must seek our views. In service user representation a different mode of engagement transpires. If professionals habitually do not listen and act on the views of service users when we are advising on policy and services then our experience of being service user representatives is the same one we feel when denied choice and control over our lives. It must also be noted that taking control by challenging poor services can take a toll on service users:

Just thinking about the impact that can have on you, not just the experience of being humiliated but the experience of trying to explain why that has an impact on you and that being disregarded as well, then that can undermine your confidence and then it becomes more and more difficult then to access services in the future.

Negative experiences become part of your private experience and can be very harmful.

Negative experiences of service user representation can push us back to the half-shadows. 


\section{Discussion, conclusions and recommendations}

We see from the results of our research that rendition of disabled service users to the half-shadows in the context of service user representation is not illusory. To facilitate our own more effective contribution to social and service change we asked questions about what would need to happen to facilitate better participation and participation outcomes. Taking these bottom-up strategies seriously would lead to better experience of service user-representation for those who take on this role with considerable potential for greater impact on changing services.

Our findings are robust being built on extensive data drawn from a diverse sample of service user representatives, some who have many years of representative experience with a wide range of organisations, others newer to the role and in the early stages of working with services in a representative capacity. One of the big advantages of our study is its scale in terms of geography as well as the range of lived experience tapped into. The established networks of Shaping Our Lives, an organisation trusted by service-users and representatives for several decades, enabled involvement of informants from diverse communities and undoubtedly aided to the success of the project. The depth and breadth of issues raised confirms that it is important to look carefully at the impact on service users of becoming service user representatives. Service user involvement should always be mutually beneficial and strategies need to be in place to make sure this is the case.

The findings from this research offer many insights for professionals seeking to maximise respectful inclusion of service users in the service user representative role. As final outputs from the project we developed three resources that will benefit those keen to take seriously what disabled people say about how our involvement as service users can be improved, in addition to the main report, a Guide for Service Providers and a Guide for Service Users. These materials, including a comprehensive list of actions based on views of research participants, can all be freely downloaded https://www.shapingourlives.org.uk/resources/our-resources/all-publications/ improving-understanding-of-service-user-involvement-and-identity

We have shown through our findings that when service user involvement is respectful and inclusive this has a positive and mutually beneficial impact for professionals and service users. However, it is also clear that when arrangements for service user involvement do not pay sufficient attention to the dismantling of barriers to participation, we experience organisational exclusion based on disabling attitudes; we are left experiencing our contribution to service development as neither adequately respected nor properly valued. Further, a problematic tension has also been uncovered whereby service user representatives notice we are sometimes treated more respectfully as a representative compared to when we are using services. This causes us to question a double standard and query if our knowledge gained through lived experience is really valued in either role.

Related to this is the finding of an often made assumption that any disabled 
person can be an effective service user representative, and our results confirm generally this is true if training and support appropriate for the role is provided. To augment our access to service user representation we conclude both participation and training should be accredited. We heard isolated good practice examples of training to develop the knowledge and confidence to take part as a service user representative; however, this was something only three people mentioned in the research. Accredited training for disabled people to build confidence for our role in service user representation would help to bring us out of the half-shadows both within, and beyond, our user representative roles.

Finally, based on our findings, we would like to disseminate Action Steps professionals can use for immediately improving service user involvement are provided which are built from the recommendations service user representatives have contributed to the research. These relate to Training, Access and ensuring Equal Participation. We propose easy Actions for Change professionals can take to immediately set about improving involvement of service user representatives. These are small, doable consistent action steps and habits that will create more respectful and inclusive service user participation and are key to making sure that people who take on the role of service user representation have positive experiences and outcomes from being involved - some will take ten minutes or less to complete! Over time they will improve involvement of service user representatives in ways that will make it more and more possible to drive through better, value for money, cost effective services that disabled people value.

Our four Essential Steps to Improving Involvement of Service User Representatives are:

Step 1. Create profiles of the service users you work with and build better connections with them

Step 2. Set some 30-day goals for improving involvement of service user representatives

Step 3. Include a call for service user involvement in any communications you send to your service user community

Step 4. Follow up and ask for feedback

Disabled service user representatives involved in our research say these steps will be the first steps in taking seriously the task of bringing us out of the half-shadows. 


\section{References}

Beresford, P. (2016) All Our Welfare. Bristol: Policy Press

Beresford, P. and Carr, S. (2018) Social Policy First Hand: An international introduction to participatory social welfare. Bristol: Policy Press

Brosnan, L. (2012) Power and participation: An examination of the dynamics of mental health service-user involvement in Ireland. Studies in Social Justice, 6, 1, 45-66

Cameron, C. (2014a) The Social Model. in C. Cameron, (Ed.) Disability Studies: A student's guide. London: Sage.

Cameron, C. (2014b) Disability research. in C. Cameron (Ed.) Disability Studies: A student's guide. London: Sage

Clark, L. (2014) Barriers. in C. Cameron, (Ed.) Disability Studies: A student's guide. London: Sage

Linton, S. (1998) Claiming Disability: Knowledge and identity. New York, NY: New York University Press

McKnight, J. (2005) Professionalised Service and Disabling Help. in I. Illich, I.K. Zola, J. McKnight, J. Caplan, and H. Shaiken (Eds.) Disabling Professions. London: Marion Boyars

Meakin, B. Cameron, C. Moore, M. and Matthews, M. (2017) Improving Understanding of Service User Involvement and Identity. [Online] https://www.shapingourlives.org.uk/ resources/our-resources/all-publications/improving-understanding-of-service-userinvolvement-and-identity London: Shaping Our Lives

Oliver, M. (1990) The Politics of Disablement. Basingstoke: MacMillan

Priestley, M. (1997) Whose research? A personal audit. in C. Barnes and G. Mercer (Eds.) Doing Disability Research. Leeds: The Disability Press, pp. 88-107

Shaping Our Lives (2018) How we work. [Online] https://www.shapingourlives.org.uk/ about/how-we-work London: Shaping Our Lives

Union of the Physically Impaired Against Segregation (UPIAS) (1976) Fundamental Principles of Disability. London: UPIAS 